324 Fresenius u. Hintz: Zur Bestimmung des Siliciums und Eisens im Kryolith.

$$
\begin{aligned}
& \text { Bequeme Darstellung von Chromchlorid. } \\
& \text { (Briefliche Mittheilung.) } \\
& \text { von }
\end{aligned}
$$

\title{
A. Vosmaer.
}

Durch Ueberleiten von Chlor über erhitztes Ferrochrom lässt sich sehr bequem Chromchiorid $\left(\mathrm{Cr}_{2} \mathrm{Cl}_{6}\right)$ in beliebigen Mengen darstellen. Man kann das Präparat auf diese Weise in sehr reinem Zustande gewinnen, denn in einem gläsernen Verbrennungsrohr lässt sich die Scheidung desselben von Eisenchlorid und von Manganchlorür leicht durchführen, da das Fisenchlorid viel leichter, das Manganchlorür aber viel schwerer flüchtig ist.

Ich benutze zur Darstellung des Chromchlorides Ferrochrom mit einem Gehalt von $21 \%$ Chrom.

Man hat darauf zu achten, dass sich die Glasröhre nicht verstopft, da sich sonst schwer flüchtiges Eisenchlorür bildet.

Das von mir in der beschriebenen Weise dargestelite Chromchlorid war völlig unlöslieh in Wasser und bestand aus sehr schönen, langen, tief seidensammetartig violettglänzenden Nadeln.

Bei dem Versuche, aus Ferrowolfram in gleicher Weise Wolframhexachlorid $\left(\mathrm{WoCl}_{6}\right)$ darzustellen, erhielt ich ein Gemisch wunderschön scharlachrother Nadeln von Wolframmonoxytetrachlorid ( $\left.\mathrm{WOCl}_{4}\right)$ und gelben Wolframdioxychlorids $\left(\mathrm{WO}_{2} \mathrm{Cl}_{2}\right)$. Das rothe Wolframmonoxytetrachlorid geht bekanntlich sehr schnell in Wolframdioxychlorid über.

Gellivara in Schweden.

\section{Mittheilungen aus dem chemischen Laboratorium des Prof. Dr. R. Fresenius zu Wiesbaden.}

\author{
Zur Bestimmung des Siliciums und Eisens im Kryolith. \\ Von
}

\section{R. Fresenius und E. Hintz.}

Kürzlich lag uns die Aufgabe vor, in Kryolithproben den Gehalt an Silicinm zu bestimmen. Wir glaubten dieser Anforderung leicht genügen $\mathrm{zu}$ können durch Zersetzen des Kryoliths mit Schwefelsäure in einem geeigneten Apparate und Leiten der entstehen- 
Fresenius u. Hintz: Zur Bestimmung des Siliciums und Eisens im Kryolith. 325

den flüchtigen Producte, Fluorwasserstoff und Fluorsilicium, in vorgeschlagene Ammoniakflüssigkeit; von jeder Verwendung von Glastheilen bei dem Apparate musste selbstverständlich abgesehen werden.

Als wir den Versuch in dieser Weise ausführten, fanden wir zu unserem Erstaunen, dass ein erheblicher Theil des Siliciums, ja weitaus die Hauptmenge, in Form feinen Sandes in dem Rückstande zurückgeblieben war, und nur relativ geringe Antheile sich verflüchtigt hatten.

Es dürfte daher die Beschreibang der schliesslich eingehaltenen Methode von allgemeinem Interesse sein.

Zum Aufschliessen der Substanz kam folgender Apparat zur Verwendung:

Als Zersetzungsgefäss diente eine Uförmig gebogene, starkwandige Bleiröhre, von etwa $19 \mathrm{~cm}$ Höhe und $2,6 \mathrm{~cm}$ lichter Weite bei $0,5 \mathrm{~cm}$ Wandstärke. Dieselbe wurde in einer Eisenschale mittelst Sandes an dem unteren, gebogenen Theil vollständig eingebettet; durch entsprechende Aufstellung wurde weiter dafür Sorge getragen, dass man das Sandbad erhitzen konute. Die beiden Schenkel des Zersetzungsgefässes waren mit durchbohrten Gummistopfen verschlossen, in welche engere Bleiröhren luftdicht eingesetzt waren. Der eine Schenkel war in dieser Weise mit einer Schwefelsäurewaschflasche verbunden, während an den anderen sich zwei dem Zersetzungsgefässe ähnliche, aber etwas engere Bleiröhren von $2 \mathrm{~cm}$ lichter Weite anschlossen. Die Verbindung mit diesen Bleiröhren war ausschliesslich mit Gummistopfen,. Bleirohr und Kautschukschlauch bewirkt, also unter Ausschluss jeder Verwendung von Glasröhren. Die letzte dieser Bleiröhren stand mit einer mit Wasser abgesperrten, gläsernen $\cup$-Röhre und weiter mit einem Aspirator in Verbindung, welcher es ermöglichte, fortgesetzt einen langsamen Luftstrom durch den Apparat zu leitèn, dessen Gang man an der gläsemen $U$-Röhre und der Schwefelsäurewaschflasche controlirte.

Es empfiehlt sich, die als Zersetzungsgefäss bestimmte Bleiröhre vor dem Gebrauch, mit etwas Schwefelsäure beschickt, anf $200^{\circ} \mathrm{C}$. zu erhitzen, damit sich die Wände derselben mit schwefelsaurem Bleioxyd überziehen. Man kann die Röhre dann ruhig mit Wasser reinigen, es wird immer noch ein genügender Ueberzug bleiben.

Zur Ausführung einer Bestimmung beschickt man die beiden engeren Bleiröhren des eben beschriebenen Apparates mit Ammoniak, gibt die abgewogene Menge der Substanz - etwa $5 \mathrm{~g}$ - in das Zersetzungsgefäss, übergiesst dieselbe mit etwa $15 c c$ concentrirter Schwefelsäure und 
326 Fresenius u. Hintz: Zur Bestimmung des Siliciums und Eisens im Kryolith.

sorgt für luftdichten Schluss des Apparates. Man setzt dann den Aspirator in Gang, so dass ein langsamer Luftstrom durch den Apparat streicht, und erwärmt nun das Sandbad auf etwa $200^{\circ}$ C., welche Temperatur man an einem gleichfalls in das Sandbad eingesenkten Thermometer controlirt. Nachdem man durch zweistündiges Erhitzen unter beständigem Durchleiten eines langsamen Luftstromes den Kryolith aufgeschlossen hat, lässt man erkalten, spült dann den Inhalt des Zersetzungsgefässes in eine Platinschale und bringt durch Erhitzen, eventuell durch Zufügen einiger Tropfen Salzsäure, die Verbindungen der Thonerde etc. jn Lösung.

Der hierbei verbleibende Rückstand, welcher die Hauptmenge der Kieselsä ure enthält, wird abfiltrirt, ausgewaschen and mit kohlensaurem Natron geschmolzen. Da der Rückstand möglicher Weise nicht frei ron Fluorverbindungen sein kann, wird in der Wasserlösung der Schmelze die alkalische Reaction durch Neutralisation mit Salzsäure unter Aufkochen fast, aber nicht vollständig abgestumpft und nun durch A.bdampfen die Kieselsäure zum grössten Theil abgeschieden. Zu dem Filtrate fügt man eine Auflösung von kohlensaurem Zinkoxyd in Ammonialk und engt die Flüssigkeit so lange ein, bis alles Ammoniak ausgetrieben ist. Die Abscheidung der Kieselsäure aus dem zuletzt erhaltenen Niederschlag geschieht in bekannter Weise durch Lösen in Salpetersäure, Abdampfen, Aufnehmen mit Salpetersäure und Abfiltriren der zurückbleibenden Kieselsäure. - Der in Wasser unlösliche Theil der Schmelze wird mit Salzsäure gelöst und auch hier die Kieselsäure in belzannter Weise abgeschieden.

Ess sind nun weiter noch die Mengen von Silicium zu bestimmen, welche, als Fluorsilicium verflüchtigt, in den mit Ammoniak beschickten Bleiröhren zurückgehalten wurden.

Bei dem Entleeren der Röhren erwies sich die ammoniakalische Flüssigkeit durch Schwefelblei und schwefelsaures Bleioxyd getrübt. Die Bildung des Schwefelbleies war bei unseren Versuchen dadurch bedingt, dass die benutzen Bleiröhren »geschwefelt «, das heisst mit einem dünnen Ueberzug von Schwefelblei versehen waren.

Um zu vermeiden, dass kleine Kieselsäuremengen der Bestimmung entgehen, wird ein so erhaltener Niederschlag abfiltrirt, das Filter sammt Niederschlag eingeäschert, die Asche mit wenigen Tropfen Salpetersäure und Schwefelsäure abgeraucht und nun das gebildete schwefelsaure Blei- 
oxyd mit essigsaurem Ammon ausgezogen. Ein etwa verbleibender Rückstand wird der zu wägenden Kieselsäure beigefügt.

Die ammoniakalische Lösung versetzt man weiter mit so viel kohlensaurem Natron, dass auch nach dem Verdampfen des Ammoniaks die Reaction deutlich alkalisch bleibt, und scheidet hier, wie oben, die Kieselsäure mit einer Auflösung von kohlensaurem Zinkoxyd in Ammoniak ab.

Die an 4, eventuell 5, verschiedenen Stellen sich ergebende Kieselsäure wird gemeinsam gewogen und durch Verflüchtigen mit Flusssäure und Schwefelsäure auf Reinheit geprüft.

Wir fanden so in 3 verschiedenen Proben Kryolith:

a.

Silicium . . 0,80\% b.

$1,23 \%$ c. $1,39 \%$

Den Gehalt an Eisen im Kryolith bestimmt man in der. Weise, dass man den Kryolith zunächst mit Schwefelsäure aufschliesst und den unlöslichen Rückstand von der schwefelsauren Lösung durch Filtration trennt. Man schmilzt den Rückstand mit kohlensaurem Natron, scheidet nach Aufweichen der Schmelze mit Wasser die Kieselsäure mit Salzsäure $a b$, gibt die salzsaure und die zuerst erhaltene schwefelsaure Lösung zusammen und oxydirt das nun vollständig in Lösung befindliche Eisen, wenn nöthig, mittelst Chlorwassers.

Durch Eintragen dieser Flüssigkeit in concentrirte, heisse Kalilauge erhält man einen kleinen Niederschlag, welcher gut ausgewaschen und hierauf in Salzsäure gelöst wird. Nach Zusatz von Weinsteinsäure lässt sich nun durch Ammon und Schwefelammonium reines Schwefeleisen fällen, welches in bekannter Weise in Eisenoxyd übergeführt und gewogen wird.

Hat man häufig derartige Bestimmungen vorzunehmen, so dürfte es sich am meisten empfehlen, die salzsaure Lösung des mit Kalilauge erhaltenen Niederschlags zu reduciren und mit Chamäleonlösung zu titriren.

In den 3 bereits oben angefürten Proben Kryolith ergab sich:

a.

Eisen . . $0,11 \%$ b.

$0,85 \%$ c.

$0,88 \%$ 